\title{
A Kaupapa Māori supervision context - cultural and professional
}

Jacquelyn Elkington

Dr Jacquelyn Elkington lectures on the Bachelor of Applied Social Work degree at Manukau Institute of Technology. Her main areas of specialty include human development, psychology, indigenous liberation, Kaupapa Māori research, counselling and supervision.

Hikurangi maunga, Waiapu awa, TeWhānau o Ruataupare te Hapū, Ko Ngāti Porou, Tararaa ngā izwi.

\section{Abstract}

This article affirms an indigenous perspective for Māori practitioners of professional supervision in the social sciences, particularly in the practice of Kaupapa Māori supervision. Definitions of supervision are discussed, Codes of Ethics are analysed and are provided a cultural response. Key problem areas of the current cultural supervision situation are identified and an analysis of those areas is deconstructed by asking questions of existing power relations within the sector. Accountability, representation, initiation, benefits and legitimization (Bishop \& Glynn, 1990) are the topics under scrutiny. The article reports on a reconstruction of some key solution areas as researched in a PhD study of Kaupapa Māori supervision, completed in 2013.

\section{Introduction}

To date, well-intentioned efforts to provide suitable supervision for Māori social work practitioners are often thwarted by a mono-cultural worldview. This article celebrates the context in which frameworks of supervision can be developed appropriately for practice in social services. One framework recently developed as a result of such context is called both 'Whānau Tautoko: He Huarahi Whakatau Mauri' and Kaupapa Māori Supervision in Social Services (KMSinSS). Te Whariki Tautoko is an Incorporated Society (since 2001) of practitioners who reflect Māori values and beliefs in social services practice. The group's input, on which the study relied for Kaupapa Māori research methodology (Smith, 1999) and practitioner perspective, provided safe, caucused space, invigorated by Kaumatua presence and wisdom. The article encourages people to grow critical mass for cultural responsiveness and Kaupapa Māori initiatives for development of social service practice, particularly in supervision. It builds on other appropriate models such as the Awhiowhio framework of supervision by Emma Webber-Dreardon (1999) and He Kōrero Kōrari by Moana Eruera (2005). The expectation of an increase in further models broadens as tangata whenua voices work smarter to meet more regularly in forums such as is currently occurring, as recently as March 2014 at Manukau Institute of Technology.

\section{Cultural supervision}

Cultural supervision was a hot topic in the early years of the 21st Century. On the back of nursing arguments for cultural safety (Wepa, 2006), curiosity grew about what constituted 
cultural competency, cultural awareness and cultural supervision. It was discussed at a professional development day organized by New Zealand Association of Counsellors on 27 September 2004, particularly with regards to the difference between cultural consultation and cultural supervision. Addressing the problem regarding how cultural supervision was being used inappropriately, at the time by some non-Māori, was necessary. This led to listing the following aspects, later published in Te Whariki Tautoko Newsletter 2004 (Elkington, 2013, p. 43) about 'Cultural Supervision - what it is not'. The summary of what Cultural Supervision is not, included the following points; a crash course in tikanga Māori, a crash course in te reo, a Treaty of Waitangi workshop, de-colonisation workshops, a novelty trip to a marae, or, a place to learn genealogy/whakapapa.

It was realized that for some practitioners, the above activities needed to be provided by cultural supervision because of the lack of Māori cultural competency in the practitioner. The definitions became clear as cultural supervision and cultural competency were defined by competency, rather than by culture.

So for those practitioners lacking competency, or wanting to develop practice in Māori cultural practice, they would be invited to participate in cultural supervision. For those practitioners wanting to grow practice in Kaupapa Māori, they would be invited to participate in Kaupapa Māori supervision. So long as participants could meet the entrance criteria of participation, they were welcome.

The criteria were few and Te Whāriki Tautoko ratifi the requirements of those who could participate in Kaupapa Māori supervision at their various research hui between 2008 and 2012. They were clear about the framework of Whānau Tautoko as an example of Kaupapa Māori supervision 'specifically aimed at supporting professionals in counselling and social services who are able to: speak te reo Māori, actively use tikanga Māori, create frameworks of practice which include articles of Te Tiriti o Waitangi, negotiate strategies in bi-cultural perspectives' (Elkington, 2013, p. 137).

However, what also emerged by the time Whānau Tautoko had completed its first trial in Nelson, 2010 (Elkington, 2013, p. 122-130), was the notion that cultural supervision was actually no different to any professional or clinical supervision. In fact, '...pprofessional supervision includes the professional development of practice ... no matter what the culture' (Elkington, 2013, p. 98). The name, role and definition of cultural supervision became redundant because clarity recognised no difference to the name, role and definition of professional supervision. Aligning them both as the same thing also prevented any risk of 'othering' or the temptation to position cultural supervision as a 'poor cousin' to professional supervision. In addition, while Māori matters need to be discussed with people who understand Māori matters, and given the 'redundancy of the term originally used to discuss this area, [resources] refer to another term called 'supervision for Māori' in preference to the term, now redundant to the description professional supervision, of cultural supervision' (Christchurch Community House, 2005).

\section{Kaupapa Māori supervision}

Kaupapa Māori supervision became a natural outcome of specialised professional supervision, once the term cultural supervision was recognised as professional supervi- 
sion. Kaupapa Māori supervision is named according to the value system on which it is based, building on the notion that, 'values, protocols and practices of [Māori] culture' (Walsh-Tapiata \& Webber, 2004, p9) are being adhered to. Such an activity assists in clarifying for whom the supervision is most appropriate. For example, some pakeha practitioners practice well, based in values of Kaupapa Māori. Some Māori practitioners practice well, based in values of non-Māori cultures. Fa'a Samoa supervision becomes clear for developing practice in Samoan ways, as Philosophy China supervision becomes clear for developing practice in a Chinese way - whether or not the practitioners are from Samoa, or China, or Aotearoa.

This notion then begged the question 'how does western supervision name itself as a culture based in western values?' At a New Zealand Association of Counsellors Research Conference held in Tauranga (2005) the question prompted a range of answers. Some participants were offended at the question. Others chose to describe possible supervision names as 'western-based ... American-based ... of British influence or mainstream' (Elkington, 2013, p. 86-98). However, the word 'mainstream' is often seen as offensive for some minority groups because the implications refer to alternative worldviews as a 'creek' or 'river' flowing off the main 'stream' and this rarely is the case. The focus group at the counsellors conference chose to use the word 'general-stream' to describe dominant, mono-cultural discourse because general refers to generally accepted worldview notions and 'specialised' might refer to a specific, named, minority worldview (Elkington, 2013).

\section{Bi-cultural supervision}

Bi-cultural supervision might refer to the supervision that allows for both cultures to be developed according to competency within each culture to work together. Little research can be found that writes about what values base a tauiwi or Pākehā culture hold and about what that actually is. It could be because Pākehā culture is all pervasive using topics like social justice, human rights, feminism etc., to assert dominance and social control through invisibility (for more information on this read about whiteness theory). So, there is little wonder there are limitations in the literature to describe what culture looks like for Pākehā people who migrated from Australia or England to live here in Aotearoa/New Zealand, as a partner in Treaty relationships with tangata whenua.

Ritchie (1999) discusses both Māori and Pākehā values as identified by his research and to base a beginning understanding of bi-culturalism. But the lists of values are only a beginning until Pākehā are more willing to make more visible the meanings of their own values for them. In the meantime, we can only develop 'By Māori, For Māori.' For example, O'Donohgue (2010), at a presentation given at the Supervision Conference in Auckland, failed to include a western or general stream positioning in his emerging cultural framework of supervision! Dialogue between Pākehā and Māori must include a shared space where tauiwi are open to acceptance, challenge and negotiation of their own values in partner relationships with tangata whenua. Probably the closest at the moment to bi-cultural supervision is a bi-lingual framework that does not compromise through translation from Māori to English, the Māori concepts of a Kaupapa Māori supervision framework. KMSinSS was able to achieve this to some degree. It is hoped that the framework will be elaborated further in future writing, this article remains only with the task of setting up appropriate environments and contexts using Kaupapa Māori research methodology for development. 
Professional supervision and clinical supervision are terms, 'often ... used interchangeably ...' (Davys, 2009) and refers to the process, according to Davys, of 'in-depth refl $\quad .$. to achieve, sustain and develop a high quality of practice ...'. Professional supervision is 'aimed at enhancing helping eff $\quad$...' (cited in Beddoe \& Davys, 2010, p. 10) and has 'retained its core functions of accountability, education and support' (cited in Beddoe \& Davys, 2010, p. 17). In summary, cultural supervision is professional supervision and Kaupapa Māori supervision is specialised professional supervision based in values from the culture of Māori.

\section{An examination of supervision in social service contexts}

\section{Supervision for counsellors}

The profession of counselling expects that counsellors work from the core values of respect for human dignity, partnership, autonomy, responsible caring, personal integrity and social justice. It expects counsellors to be reflective in developing effective and ethical practice. The New Zealand Association of Counsellors provides its members supervision with aims of monitoring, mentoring, supporting and administering contracts that are, 'collaborative ... confidential ... and based upon informed consent [taking] a number of forms, including individual or group ... may involve telephone, email and letters' (NZAC Code of Ethics, 2012, Section 9). Mentions of cultural supervision have been suitably extracted from the code of ethics since its review in 2009. Such development has occurred due to the efforts NZAC have made to collaborate with Te Whariki Tautoko on the notion that cultural and professional supervision are the same. After all, cultural aspects to supervision should permeate all types of supervision 'and not just left for cultural supervision' (Walsh-Tapiata \& Webber, 2004, p.3). NZAC generally share positive bi-cultural relationships with Te Whariki Tautoko, a close affiliate association of Māori practitioners and continue to make genuine efforts to strengthen connections.

\section{Supervision for social workers}

For the social work profession, expectations of practitioners are structured around eight responsibilities outlined in detail by Aotearoa/New Zealand Association of Social Workers (ANZASW). They begin with practitioner responsibility to Te Tiriti o Waitangi-based society and end with the responsibility for research and publications. We know still that 'Māori experiences of supervision and supervision training in Aotearoa have primarily been provided from a western mono-cultural framework' (Walsh-Tapiata \& Webster, 2004, p1). There is an increasing number of Māori receiving Kaupapa Māori supervision from Māori organisations such as Te Whariki Tautoko, Whare Tiaki Hauora, Poutiri Trust and others. But, unless the supervisors are recognised by tauiwi professional bodies and/or are members, which is often not the case, the work is most usually un-funded and Māori practitioners forage for resources to pay.

Some Māori account to non-Māori about their Māori cultural social work development and this accounting may not be ideal. Unfortunately, for social work supervision it could be argued that, 'discourses of bi-culturalism' and 'supervision practices ... such as cultural supervision ... and Kaupapa Māori supervision' have been 'othered' from western supervision and not counted as professional or clinical supervision (O'Donoghue, 2010).

To add further salt to the wound, the influence of a bi-cultural nature in, 'the Aotearoa New Zealand context' occurs only when such specialist knowledge has 'prevalence' or par- 
ticipant 'connection' or 'exposure' to 'Māori and different ethnic and cultural communities' (O’Donoghue, p. 3). Often frameworks do not include examination of a mono-cultural positioning nor do supervisor and supervisee development include an update of mono-cultural qualifications to include bi-cultural components of tikanga Māori. Implications of 'cultural competence within supervision' described a 'complexity of cultural discourses' and included how supervision might contribute to the 'development of practitioners' and the contribution to 'the cultural competence of practitioners from dominant cultural groups' (p.7). On the continuum of cultural competence some practitioners described above might border on 'cultural destructiveness, cultural incapacity or cultural blindness' (McFarlane, 2010, p.9). A more intensive up-skilling might be required than what can be provided through a few sessions of cultural supervision.

\section{Supervision for psychologists}

The profession of psychology expects from practicing psychologists quality, education and research in psychology. The New Zealand Psychologists Board is the regulatory authority appointed under the Health Practitioners Competence Assurance Act 2003 in regard to the profession (Ministry of Health, 2013). The principal purpose of the Board is to enforce the Act to protect the health and safety of members of the public by providing for mechanisms to ensure that psychologists as health practitioners are competent and fit to practise (NZPB, 2013). The New Zealand Psychological Society offers its membership professional development, representation, advocacy, networking opportunities and various other benefits (NZPS, 2013).

The Board is concerned about avoiding the misuse of scope, eg Clinical Psychologist scope, by employers to exclude workers, such as Family Court practitioners, from practising. They are clear in their statement that 'practice is not restricted by scope, but by competence' and the Board discourages lack of access to experts denied work on that basis. Their Code of Ethics has been updated recently to include a value statement and practice implications for relations between Māori and non-Māori.

The Society has also established a National Standing Committee on Bicultural Issues (NSCBI) to advise re workshops on cultural justice and bi-culturalism. Discrepancies still exist though. Qualifications, training and registration are required to practice psychology. But to work with Māori, the only need is to 'seek advice' and for odd reasons like, '... to show respect for the dignity and needs of Māori in their practice' (NZPS, 2013, Section 1.3.2), rather than to provide quality practise, education and research, as are the aims are for working with the general public.

\section{Supervision for psychotherapists}

Central to ethical practice of the psychotherapy profession are integrity, trust and respect. The New Zealand Association of Psychotherapists Board (NZAPB) is part of the New Zealand Association of Psychotherapists (NZAP). They recognise that 'the partners of Te Tiriti o Waitangi/The Treaty of Waitangi in Aotearoa/New Zealand have different paradigms and worldviews.' Māori are mentioned as tangata whenua and as a partner in the Treaty. There is no mention, however of the other partner as non-Māori or tauiwi or pakeha or the Crown. Nor is the recognition clear about the relationship based on the difference mentioned. While only one partner, Māori has been acknowledged, without clarity about the other partner, nor the partnership - at least a bridging opportunity presents itself. 


\section{Key problem areas}

In summary, based on the brief examination of cultural supervision and of the supervision in the various social services contexts mentioned above, the following key problem areas still exist, particularly from the perspective of practitioners reflecting Māori values and beliefs in social services practice. Some of the problem areas are:

- Low visibility that models of supervision reinforce mono-cultural values from a western origin.

- Low mono-cultural self-awareness and acknowledgement of their contribution to ineffective social service delivery

- Oppression and dilution of Kaupapa Māori supervision models due to unsafe and unprotected environments.

- Inappropriate research methodology that does not enable Kaupapa Māori interpretation or analysis for appropriate development.

Care has been taken by the author to deconstruct the supervision situation (not people) and to externalise the issues (outside of people) so we can better understand the needs for supervision. Other Māori practitioners may have different opinions and priorities with the way the issues have been outlined here, but my interpretation is only a general attempt from one perspective, with no intention to discount or discredit the good work completed by others.

\section{A preference for Kaupapa Māori supervision in social services contexts}

It is important to investigate aspects of power relations to better inform the preference context for Kaupapa Māori supervision. Russell Bishop (1999) analysed similar relations in an educational context and identified five issues that can be applied directly to the supervision situation. The issues are accountability, representation, initiation, benefits and legitimisation, and initiated an appropriate context for the conceptualising and developing of the framework in Kaupapa Māori supervision, KMSinSS.

\section{Accountability}

To whom, or what, is supervision accountable? At the present, cultural supervision is accountable to various codes of professional bodies based from western mono-culture. Practitioners often heading those professional bodies also represent the dominant discourse of western culture and to whom practitioners reflecting Māori values and beliefs too, are accountable. In none of the professions examined is there acknowledgment of accountability to ngā atua (supreme forces), ki nga whānau, hapū, iwi (immediate or extended family) or to tikanga-a-iwi (embracing difference among tribes). Nor are tribal worldviews considered for accountability measures as possible preferred codes of ethics.

\section{Representation}

Are Māori interests, needs and preferences represented in supervision? Whose voice is represented? It can be argued that at present, a mono-cultural voice is often represented. Māori interests, needs and preferences are often being overlooked, due to lack of knowledge and authority, and consequently which supervision is in question. The culture in 'cultural supervision' may be Māori 'culture' except to be differentiated from real supervision on an excuse that it is cultural. The term's redundancy becomes more necessary. 


\section{Initiation}

What perspective initiated cultural supervision? It might be fair to say that non-Māori perspective initiated cultural supervision given that Māori culture may not be reflected in terms of accountability or representation. Often cultural supervision has been initiated to address Māori cultural issues in professional practice by those non-Māori for whom Māori culture might be an issue. Certainly cultural supervision might have this aim for non-Māori to address cultural issues for non-Māori, or for Māori to do the same work, who do not closely affiliate to Māori culture (and there are a wide range of valid reasons why many do not).

However for Māori practitioners who do closely affiliate to Kaupapa Māori, and who are competent in te reo me ōna tikanga, Māori culture is not a problematic issue. So to impose the same aim might be inappropriate. All professional and clinical supervision requiring same level knowledge and skills, should be included in the cultural supervision arena for development - whether the culture is Māori, Yugoslavian, Persian, Samoan, Chinese, Tongan, Indian, or Pāakehā.

\section{Benefits}

Who benefits from cultural supervision? From the professions discussed, the groups that benefit most are those who have limited or no knowledge of Māori practices and language. Current cultural supervision highly benefits this group but the knowledge can be shortchanged and is often exploited to fit into supervision sessions that shares specialist information better taught over a period of time equivalent to a diploma or degree programme.

\section{Legitimisation}

What perspectives are legitimised? Who theorises about what is legitimate in the nature of supervision? Simply answered, the mono-cultural, western, dominant perspectives are legitimised in supervision practice from the professions examined.

It is no longer acceptable to legitimise social services and supervision practice from western-based, mainstream values as the standard worldview against which all other worldviews are measured. The need to call what Māori do as 'cultural' is misleading when, in fact, all things are cultural and there isn't any difference in legitimacy between the two. Similarly, is the seriousness of choosing ice-cream. Vanilla ice-cream names itself as a flavour of icecream based on 'values' of colour, texture, taste, packaging and brand. Chocolate ice-cream, strawberry, lime and banana are all legitimate flavours of ice-cream based on similar values, differing perhaps in price and/or accessibility. Point is, vanilla is only one flavour of many flavours of ice-cream - it does not claim to be the only legitimate flavor over all the others.

It is no longer acceptable for Western approaches to maintain dominant roles that are so much in plain sight, they become hidden or invisible then assume a position of superiority against which all 'other' frameworks must measure. If supervision was given a generic, broad definition of supervision, then each community of supervision (not excluding general stream) could fairly assert self-determination in describing their own processes. Making visible the values upon which those processes are based helps name the process accordingly. Just as cultural supervision refers to Māori values so must general stream supervision make itself visible as it refers to general stream values - as one perspective of many, and not as the only perspective. Cultural supervision is an appropriate place in which to locate difference and so the naming and 'visibility' of the dominant culture must be the same for all partner cultures not just for Māori culture. 
Overall, there are efforts being made by all professions to articulate in policy and value statements a more legitimate voice to represent worldview of Māori through meaningful accountability and benefits initiated by Māori. Such investigation developed by Bishop \& Glynn (1999) has been necessary in the re-positioning of Māori voice to balance more power relations that exist and ensure they are more aligned towards a more equitable relationship for both Māori and non-Māori.

\section{Key solutions areas}

The examination of the current supervision situation in various professions has been telling. The investigation of power relations operating here, identifies following key solution areas for constructing ways forward as summarised:

- High visibility of mono-cultural values in models of supervision from western origin.

- High mono-cultural self-awareness and acknowledgement of their contribution to ineffective social service delivery as evidenced by high statistics of Māori service use.

- Revival and creation of more Kaupapa Māori supervision models within safe and protected environments.

- Appropriate Kaupapa Māori research methodology, particularly of bi-cultural initiatives in Kaupapa Māori, to enable appropriate interpretation and analysis for appropriate development.

In implementing the solution areas named above, the article turns to Paulo Freire (1995) to pave the way forward in working with those with whom there is a struggle for power and a resistance to share a space of courageous and respectful dialogue. Friere off the quote below:

It is only the oppressed who, by freeing themselves, can free their oppressors. The latter, as an oppressive class, can free neither others nor themselves. It is essential that the oppressed wage the struggle ... resolved by the appearance of the new man: neither oppressor nor oppressed, but man in the process of liberation (Freire, 1995, p. 48).

It is to this end that we, tangata whenua as the oppressed, must wage the struggle, to restore humanity in a bi-cultural society, so that liberation with tauiwi becomes the work and joy of both cultures 'in the process of liberation.'

\section{Conclusion}

The article has identified key solution areas to some key problem areas for the cultural supervision situation existing at present, particularly from the perspective of practitioners who reflect Māori values and beliefs in practice. Some of the tasks identified by Māori for non-Māori to work on and develop, at such time that only non-Māori can decide, included a need for high visibility and self-awareness of mono-cultural values and their contribution to ineffective social service delivery particularly when faced by the high statistics of Māori service use. Some of the tasks identified by Māori for Māori, are the revival and creation of more Kaupapa Māori supervision models within safe and protected environments. Some frameworks might need to use an appropriate Kaupapa Māori research methodology, particularly of bi-cultural initiatives in Kaupapa Māori, to enable appropriate interpretation and analysis for appropriate development. 
Acknowledgements. Te Whariki Tautoko Incorporated Society Executive Committee and membership: Hinekahukura Aranui (Ngati Maniapoto), Trevor Wilson (Ngati Kuia), Taima Moeke-Pickering (Ngati Pukeko) , Kahuwaeroa Katene (Ngati Toa), Pirihia Paul (Ngati Koata), Matewawe Pouwhare (Ngai Tuhoe), Maria Ranga (Tainui), Rawiri Waretini-Karena (Tainui), Jane Du Feu (Taranaki). Also to management and staff at Manukau Institute of Technology: Shirley Ikkala (Ngati Whaatua ki Orakei), John Hancox, John Merito (Te Arawa), Luana Te Hira (Ngati Kahungunu, Waikato), Dr Leland Ruwhiu (Ngati Porou). Te Wananga o Aotearoa Staff: Dr Betty-Lou Iwikau (Ngati Raukawa); Gladys Elkington (Ngati Koata), Taina Pohatu (Ngati Porou), Hariata Pohatu (Ngati Porou), Wheturangi Tapiata-Walsh (Taranaki), Mereana Te Ahuahu (Ngati Hine/Tainui), Norma Anderson (Argentina).

\section{References}

Aotearoa/New Zealand Association of Social Workers. (2013). Code of ethics. Retrieved 28 October 2013 from http:/ / anzasw.org.nz/.

Beddoe, L. \& Davys, A. (2010). Best practice in professional supervision: A guide for the helping professions. Amazon. com: Jessica Kingsley Publishers.

Bishop, R., \& Glynn, T. (1999). Culture counts: Changing power relations in education. Palmerston North, New Zealand: The Dunmore Printing Company Ltd.

Child, Youth and Family. (n.d). What is professional supervision? Practice centre, a practice resource for Child, Youth and Family. Retrieved 9 September 2013 from http:/ / www.practicecentre.cyf.govt.nz/policy/professional-supervision/key-information/what-is-professional-supervison.html.

Christchurch Community House. (2005). Supervision in the voluntary sector: An overview of what it is and how to make it happen. The Supervision Directory Steering Group, Christchurch Community House, Te Whakaruruhau ki Otautahi: Christchurch, New Zealand.

Davys, A. M., \& Beddoe, L. (2009). Interprofessional learning for supervision: 'taking the blinkers off'. Learning in Health and Social Care, 8: 58-69. doi: 10.1111/j.1473-6861.2008.00197.x.

Durie, M. (1994). Whaiora. Maori health development. New York, New York: Oxford University Press.

Elkington, J. (2013). Kaupapa Maori supervision in social services and the implications of culture for wholistic well-being. Whakatane, New Zealand: Te Whare Waananga o Awanuiarangi, Unpublished PhD Thesis, Volumes 1 \& 2.

Eruera, M. (2005). He Korero Korari. Supervision for Maori. Weaving the past into the present for the future. Auckland: Massey University, MPhil (Social Work) Thesis.

McFarlane, A. (2010). Components of cultural supervision. New Zealand Psychologists Board. Retrieved 9 September 2013 from http:/ / www.psychologistsboard.org.nz.

Mead, H. M. (2003). Tikanga Maori. Living by Maori values. Wellington, Aotearoa/New Zealand: Huia Publishers.

Ministry of Health. (2013). Health Practitioners Competence Assurance Act, 2003. Retrieved 28 October 2013 from http:/ / www.health.govt.nz.

New Zealand Association of Counsellors, NZAC. (2012). Code of ethics. Retrieved 27 October 2013 from http:// www.nzac.org.nz/code_of_ethics.cfm.

New Zealand Association of Psychotherapists, NZAP. (2013). Code of ethics. Retrieved 28 October 2013 from http:/ / nzap.org.nz/.

New Zealand Psychological Society, NZPS. (2002). Code of ethics. Retrieved 27 October 2013 from http://www. psychology.org.nz.

New Zealand Psychologists Board, NZPB. (2003). Scopes of practice.Retrieved 27 October 2013 from http:/ / www. psychologistsboard.org.nz.

O'Donoghue, K. (2010). Social work supervision in Aotearoa/New Zealand. Auckland, New Zealand: Proceedings of Supervision Conference, ANZASW.

Ritchie, J. (1999). Becoming bicultural. New Zealand: Huia Publishers.

Social Workers Registration Board. (2013). Competence to practice social work with Maori. Retrieved 28 October 2013 from http:/ / www.swrb.govt.nz/.

Walsh-Tapiata, W., \& Webster, J. (2004). Te mahere: The supervision plan. Te Rau Tipu Ora Child and Adolescent Mental Health Workforce Development. Retrieved 10 February, 2006 from www.matatini.co.nz/publications/ series4/Training-Workplace\%20Nexus.pdf - Similar pages.

Webber-Dreardon, E. (1999). He taonga mo o matou tipuna (A gift handed down by our ancestors): An indigenous approach to social work supervision. Te Komako Social Work Review, 11(4), 7-11.

Wepa, D. (2006). Cultural safety and the birth culture of Maori. Te Komako Social Work Review, Hotoke: $26-31$.

Wilson, T. (2004). Cultural supervision. Nelson, New Zealand: Proceedings of New Zealand Association of Counsellors Conference, NZAC. 